\title{
Heavy metals in the Dead Sea and their coprecipitation with halite
}

\author{
M. Stiller ${ }^{1}$ \& L. Sigg ${ }^{2}$ \\ ${ }^{1}$ Weizmann Institute of Science, Rehovot 76100, Israel; Present address: 5 Haem str. Rishon LeZion \\ 75240, Israel; ${ }^{2}$ EAWAG, CH 8600 Dubendorf, Switzerland
}

Key words: heavy metals, halite, coprecipitation, Dead Sea

\begin{abstract}
After a prolongued period of stratification (about 300 years) the Dead Sea overturned in 1979 and again in 1982. Its waters became saturated with respect to halite and the massive precipitation of halite which occurred in winter $1982 / 83$ has been monitored. We followed the fate of the heavy metals during this period of physical and chemical changes.

The concentrations of $\mathrm{Zn}, \mathrm{Cd}, \mathrm{Pb}$ and $\mathrm{Cu}$ in the Dead Sea waters have been measured by anodic stripping voltammetry (ASV) which provided sensitive measurement of these elements after a minimal pretreatment of the samples (dilution 1:1 and acidification). In the meromictic lake (prior to 1979), the concentrations of all four elements were larger in the deep anoxic layers. With the onset of halite precipitation a decline in their concentrations was observed. Most dramatic was the decrease in $\mathrm{Cd}$, which practically disappeared from the water column in 1985. The coprecipitation of heavy metals with halite - collected by sediment traps in 1983 - was examined, as well as that of older halite recovered from a sediment core. Although concentrations of heavy metals were somewhat larger in recent halite, all halite samples had the same coprecipitation pattern: the concentration of $\mathrm{Pb}$ was the largest, followed by $\mathrm{Cd}$, and that of $\mathrm{Cu}$ was the smallest. The apparent distribution coefficient was larger for $\mathrm{Cd}$ than for $\mathrm{Pb}$.

We estimated the amount of $\mathrm{Cd}$ which may have accompanied the deposition of halite during 1983-1985; it is compatible with its observed disappearance from the water column in 1985 . The amounts of $\mathrm{Pb}$ and of $\mathrm{Zn}$ which are missing from the Dead Sea of 1985 are much larger than can be accounted for by coprecipitation with halite. A possible explanation is that the formation of halite crystals may have enhanced settling of particulates which in turn, may have scavenged $\mathrm{Pb}$ and $\mathrm{Zn}$ from the Dead Sea waters. $\mathrm{Cu}$ seems to be much less affected by the physical and chemical events which occurred in the Dead Sea during 1976-1985.
\end{abstract}

\section{Introduction}

The hypersaline Dead Sea overturned in 1979 (Steinhorn et al., 1979; Steinhorn, 1985) after a prolongued period of about 300 years of meromictic stratification (Stiller \& Chung, 1984). Then a short meromictic episode followed (Stiller et al., 1984a) and the Dead Sea overturned again in
1982. Since then the Dead Sea has been monomictic (Anati et al., 1987).

Until 1979 a relative dilution and oxic conditions prevailed in the upper water mass, while the deep waters were anoxic (Neev \& Emery, 1967). The chemical composition of the major ions was very similar in both water masses: $\mathrm{Cl}>\mathrm{Br}>>$ $\mathrm{SO}_{4}>\mathrm{HCO}_{3}$ and $\mathrm{Mg}>\mathrm{Na}>\mathrm{Ca}>\mathrm{K}$. At the 
1979 overturn the average salinity was $340 \mathrm{~g} \mathrm{l}^{-1}$ and that of the most abundant ion, $\mathrm{Cl} 225 \mathrm{~g}^{-1}$.

During the overturn of 1979 precipitation of halite was observed at the Dead Sea surface (Steinhorn, 1983); in 1982 the brines became saturated with respect to halite (Anati et al., 1987) and as documented by sediment traps (Stiller, Gat \& Spencer, pers. commun.) the winter of $1982 / 1983$ marked the onset of a heavy precipitation of halite. The published data on minor and trace elements in the Dead Sea are relatively scarce (Bentor, 1961; Schonfeld \& Held, 1965; Brooks et al., 1967; Nissenbaum, 1977) and sometimes controversial (Stiller et al., 1984b).

The physical changes and the chemical evolution which took place recently in the Dead Sea have influenced the distribution of the heavy metals in its water column and may perhaps explain some of the controversy in the published data.

We have attempted to follow the fate of the heavy metals $\mathrm{Zn}, \mathrm{Cd}, \mathrm{Pb}$ and $\mathrm{Cu}$ in the brines of the Dead Sea during the years 1976-1985 and the extent of their coprecipitation with halite.

\section{Description of study site}

The Jordan River which combines the outflow of Lake Kinneret with that of the Yarmouk River supplied until the early 1960's two thirds of the Dead Sea's total inflow. Seasonal floods, small rivers, like the Arnon from the east, a few freshwater and saline springs and scarce rainfall - only 50-70 mm year ${ }^{-1}$ - accounted for the rest. In 1964 the outflow from Lake Kinneret was diverted; the diminished discharge of the Jordan River caused a steady decline in the level of the lake. In 1976 brines from the deep northern basin of the lake ceased to cross over the sill of the Lisan Straits into the very shallow southern basin (Fig. 1) which began to dry up.

At present, most of the southern basin has been transformed into a series of diked, solar evaporation ponds, into which brines from the deep northern basin are being pumped. Halite, and at a later stage carnallite, from which potash is then extracted, precipitate in the evaporation ponds. After the deposition of carnallite, the residual concentrated brines, called End Brines, are pumped back into the Dead Sea.

A chronology of the state of the water column in the northern basin during 1976-1985 is given below as a necessary background to interpret the heavy metals behavior. In January and in June 1976 the upper mixed layer was $80 \mathrm{~m}$ thick, the transition zone was between 80 and $110 \mathrm{~m}$ and the deep waters, 110 to $300 \mathrm{~m}$ were anoxic. In 1978 the meromictic pycnocline deepened to $175 \mathrm{~m}$ and the transition layer was between 175 to $200 \mathrm{~m}$. The deeper waters, below $200 \mathrm{~m}$ were still anoxic as indicated by presence of divalent iron (Nishri \& Stiller, 1984), but the odor of $\mathrm{H}_{2} \mathrm{~S}$ (there are no analytical data on its concentrations) was already very faint. In February 1979 as the Dead Sea overturned, the water column became homogeneous. The winter of $1979 / 80$ brought many floods which initiated a short meromictic phase until December 1982. The upper $20 \mathrm{~m}$ were about $3 \%$ less saline in December 1980 than deeper waters. In September 1982 this upper layer became close to saturation with respect to halite and its salinity was comparable to that of the deep waters. At our last sampling in May 1985, after the turnovers of December 1983 and of December 1984, the water column was well mixed with the exception of a seasonal pycnocline at $15 \mathrm{~m}$ depth.

\section{Materials and methods}

\section{Sampling and sample preparation}

Dead Sea brines were sampled at about $31^{\circ} 35^{\prime} \mathrm{N}, 35^{\circ} 25^{\prime} \mathrm{E}$ in $1976-1980$ and at the site of a permanently anchored buoy (Fig. 1) in 1982 and 1985. Hydrobios plastic samplers, equipped with protected and unprotected thermometers (manufactured by Gohla-Kiel) were used. The Dead Sea samples were collected in screwcapped glass bottles, precleaned with dilute hydrochloric acid and thoroughly rinsed with bidistilled water. The samples were stored in a dark, relatively cool $\left(22-23^{\circ} \mathrm{C}\right)$ place. 

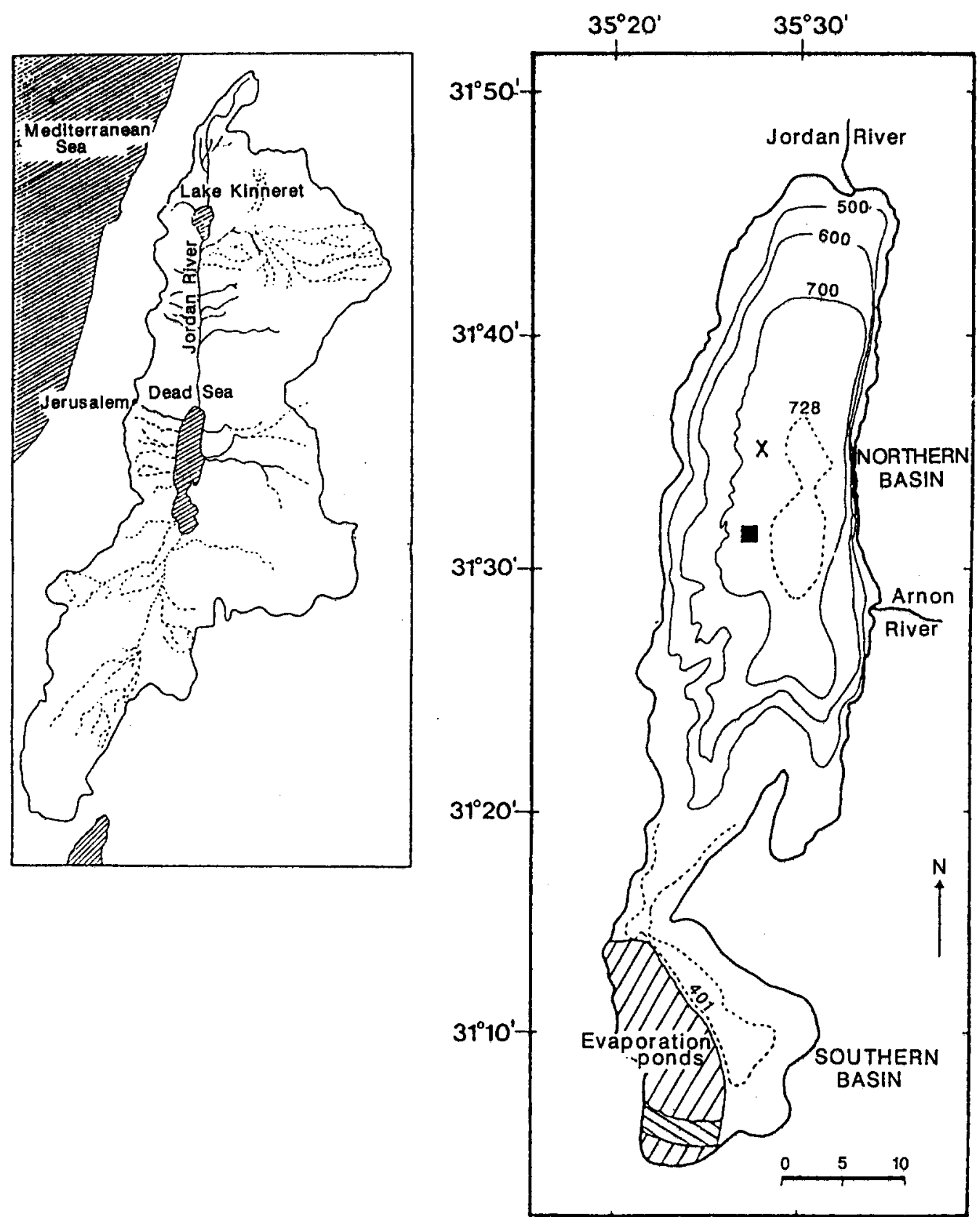

Fig. 1. Map of the Dead Sea and its catchment area (left). Shoreline corresponds to the $-398 \mathrm{~m}$ level; isodepths contours are meters below sea level; scale in $\mathrm{km}$. Site of the anchored buoy is marked by a square. Sampling site of core B1 is marked by $\mathrm{X}$.

Halite formed in the Dead Sea was collected by cylindrical sediment traps deployed at the site of the anchored buoy (Fig. 1) at $70 \mathrm{~m}$ depth of water, from February 8 to March 8, 1983. The halite crystals were separated from particulate material which settled at the bottom of the sediment trap, by passing the slurry through a $200 \mu \mathrm{m}$ nylon mesh and rinsing with about $200 \mathrm{ml}$ Dead Sea brine from $70 \mathrm{~m}$ depth, immediately after recovery of the sediment traps. The halite crystals were then transferred from the nylon mesh into a precleaned glass container. 
Core $\mathrm{B} 1,1.8 \mathrm{~m}$ length, was recovered in December 1980 at a depth of $318 \mathrm{~m}$ at $31^{\circ} 35^{\prime} \mathrm{N}$, $35^{\circ} 27^{\prime} \mathrm{E}$ (Fig. 1). Large halite crystals were found at $80-85 \mathrm{~cm}$ depth of sediment. One large crystal, $4.17 \mathrm{~g}$, was taken for analysis.

The concentration of $\mathrm{Zn}, \mathrm{Cd}, \mathrm{Pb}$ and $\mathrm{Cu}$ were measured by anodic stripping voltammetry (ASV) with the Metrohm 646 VA Processor and by using the method of standard additions. The ASV analysis of all the brines and halite samples were performed at EAWAG - Dubendorf in May-July 1985 , as well as the analysis of one sample of Lake Kinneret water and one sample of End Brine.

Prior to ASV measurement unfiltered brine samples were diluted $1: 1$ by volume with distilled water and $20 \mathrm{ml}$ were acidified with $40 \mu \mathrm{l} 5 \mathrm{M}$ $\mathrm{HCl}$ (pH 1.1). Halite crystals, 5 to $25 \mathrm{~g}$, were treated as follows: they were washed three times with triple distilled water, dried on Kleenex tissues, weighed, dissolved in triple distilled water and brought to volume in volumetric flasks. The exact weight of halite was checked by $\mathrm{Cl}$ analysis of these solutions. An aliquot of $20 \mathrm{ml}$ was acidified with $40 \mu \mathrm{l} 5 \mathrm{M} \mathrm{HCl}$ and taken for ASV analysis.

\section{Anodic stripping voltammetry measurements}

The solutions were purged initially with nitrogen for 10 minutes in the measuring vessel and for 60 seconds prior to each repetitive ASV run performed on the same aliquot. The measuring conditions were 90 seconds reduction time at a reduction potential of $-1.15 \mathrm{~V}$ or $-0.9 \mathrm{~V}$. Fresh dilutions of standard additions (spikes) were prepared daily for all four elements with triple distilled water.

The measuring sequence was: 2 to 4 repetitive runs for the unspiked sample and 2 repetitive runs after each addition of a set of spikes (standard additions of all 4 elements). Two sets of standard additions were performed for each analysis. The final dilution due to the standard additions was $1 \%$.

The analytical blank was triple distilled water acidified with $40 \mu \mathrm{l} 5 \mathrm{M} \mathrm{HCl}$. $\mathrm{Cd}, \mathrm{Pb}$ and $\mathrm{Cu}$ were undetectable and $\mathrm{Zn}$ was about $0.1 \mu \mathrm{g}^{-1}$.
The reproducibility of repetitive ASV runs was usually better than $3 \%$, mostly between $0.3 \%$ and $1.8 \%$. The concentrations of the heavy metals were calculated by linear regression, taking the data of all unspiked and spiked runs. The correlation coefficient was always better than 0.99 . However, replicate analysis of different aliquots from the same brine sample were not as good (see Table 1) as one would expect from the analytical precision indicated above. Moreover, our methodology did not control sampling artifacts and the preservation of samples for the time lapse between sampling and the date of ASV measurement.

Typical ASV sensitivities, $\mathrm{nA} \mu \mathrm{g}^{-1} \mathrm{l}$ (nanoAmpere per microgram per liter), and peak potentials, $\mathrm{mV}$ (millivolts), vs. a $\mathrm{Ag} / \mathrm{AgCl}$ reference electrode in the $1: 1$ diluted brines were: 2.1 and -980 for $\mathrm{Zn}, 2.2$ and -640 for $\mathrm{Cd}, 1.1$ and -440 for $\mathrm{Pb}$ and 1.3 and -250 for $\mathrm{Cu}$. The sensitivity of the ASV analysis in the $1: 1$ diluted Dead Sea water was thus 50-70\% (for different elements) of the sensitivity in a dilute ionic medium ( $0.01 \mathrm{M}$ nitric acid). In the undiluted Dead Sea water, after acidification, the sensitivity was lowered by a factor of about 2 . The reproducibility and the sensitivity of the data were best in $1: 1$ diluted, acidified Dead Sea water, with reduction at $-1.15 \mathrm{~V}$. Some samples were measured with $-0.9 \mathrm{~V}$ reduction potential in order to avoid the reduction of $\mathrm{Zn}$ which was present at much higher concentrations than the other heavy metals.

\section{Results}

Complexes of heavy metals in the Dead Sea

Peak potentials obtained for the heavy metals in different media give some indications of their speciation. The most probable complexes in Dead Sea water are chloride complexes; in undiluted Dead Sea water, the concentration of chloride is approximately $6 \mathrm{M}$. The potential shift observed between the diluted and undiluted Dead Sea samples may be used to evaluate the existing complexes. 
The potential shift with respect to the uncomplexed metal due to the complexation by a ligand $\mathrm{X}$ is given by the equation:

$$
\begin{aligned}
& \Delta \mathrm{E}=(R T / n F) \ln K-(R T / n F) p \ln [\mathrm{X}]+(R T / n F) \\
& \ln \left(\mathrm{D}_{\mathrm{M}}\right)^{1 / 2} /\left(\mathrm{D}_{\mathrm{c}}\right)^{1 / 2}
\end{aligned}
$$

where $R=$ gas constant, $T=$ temperature, $F=$ Faraday constant, $K=$ complex formation constant, $n=$ number of electrons in reaction, $p=$ number of ligands in complex $\mathrm{MX}_{\mathrm{p}}$ and $\mathrm{D}_{\mathrm{M}}$, $D_{c}$ are the diffusion coefficients of the free and of the complexed metal ion (Bard \& Faulkner 1980).

If we assume that the potential shift between diluted and undiluted samples is mostly due to the difference in concentration of the ligand and that the same complex is predominant at both dilutions, information about the number of ligands $p$ may be gained. The following average potential shifts $\Delta \mathrm{E}$ between diluted and undiluted Dead Sea samples were found: i) for $\mathrm{Zn}, \Delta \mathrm{E}=19 \mathrm{mV}$, which corresponds to $p=2$ and suggests the presence of $\mathrm{ZnCl}_{2}^{0}$; ii) for $\mathrm{Cd}, \Delta \mathrm{E}=39 \mathrm{mV}$ which corresponds to $\mathrm{CdCl}_{4}^{2-}$ complexes $(\Delta \mathrm{E}$ calc. $=36 \mathrm{mV}$ ). iii) for $\mathrm{Pb}, \Delta \mathrm{E}=53 \mathrm{mV}$, which is higher than calculated $\Delta \mathrm{E}=36 \mathrm{mV}$ for $\mathrm{PbCl}_{4}^{2-}$ and may include some contributions from a difference in complexation constants; iv) the peak for $\mathrm{Cu}$ measured at the electrode corresponds to the oxidation of $\mathrm{Cu}(\mathrm{O})$ to $\mathrm{Cu}(\mathrm{I})$, as oxidation to $\mathrm{Cu}$ (II) cannot be observed in this medium. For $\mathrm{Cu}, \Delta \mathrm{E}=46 \mathrm{mV}$ lies between the values calculated for $\mathrm{CuCl}_{2}^{1-}(36 \mathrm{mV})$ and for $\mathrm{CuCl}_{3}^{2-}$ $(54 \mathrm{mV})$. Since $\mathrm{Cu}(\mathrm{II})$ is expected to be present in the original samples, these measurements do not allow conclusions about the actual speciation of $\mathrm{Cu}$.

Heavy metals in the Dead Sea brines: 1976-1985

The concentrations of heavy metals measured in 8 samples of Dead Sea brines are summarized in Table 1.

In 1976 and in 1978 while the lake was still meromictic, the concentrations of the metals were generally higher in the deep anoxic waters, below
$110 \mathrm{~m}$ and $200 \mathrm{~m}$ depth in 1976 and 1978 respectively, with the exception in 1976 for $\mathrm{Cd}$, but the latter could be an artifact due to poor preservation (see Discussion). Also, the distribution of $\mathrm{Pb}$ in 1978 is unclear, either for the same reason or due to chemical interactions which accompanied the destratification. The samples of August 1978 were found to be contaminated with $\mathrm{Cu}$ by the sampling procedure: during this cruise Dead Sea brines were collected in $\mathrm{Cu}$ pipes for helium 3 analysis; prior to this sampling the pipes were flushed with the respective brine which was not discarded but stored for chemical analysis.

After 1979 the concentrations should and generally do (with the exception of $\mathrm{Zn}$ ) indicate homogenation of the water column. Concentrations, estimated by mixing the content of the stratified water column in 1978 , vs. measured concentrations in the post-overturn Dead Sea of 1980 ( $\mu \mathrm{g}^{-1}$ ) were: $\mathrm{Zn} 259$ vs. 298 ; Cd 0.73 vs. 0.75 ; $\mathrm{Pb} 16.7$ vs. 17.8 and $\mathrm{Cu} 5.0$ vs. 6.2 (the data of 1976 was taken for the estimate of $\mathrm{Cu}$ ). In May 1985 the Dead Sea was well mixed and we consider the one sample which was analysed to be fairly representative for the state of the water column after two and a half years of continous halite precipitation. A very sharp decrease in concentration is observed for $\mathrm{Cd}$ and for $\mathrm{Pb}$, a more moderate one for $\mathrm{Zn}$, while $\mathrm{Cu}$ appears to be almost unaffected. It would have been useful, of course, to have some more post-halite data, e.g. for the water column in 1983 and 1984. Comparison with the scarce earlier data (summarized by Stiller et al., 1984b) is quite difficult because most of them refer to samples taken at earlier dates than those of the present study. In the meantime, temporal and depth variations in the concentrations of the heavy metals might have taken place in response to the partial diversion of water from the Jordan River (the diversion caused continous lowering of the lake level and deepening of the meromictic pycnocline). However, the $\mathrm{Zn}$ content of the deep waters, namely $288 \mu \mathrm{g}^{-1}$ (Brooks et al., 1967), is comparable to that of 1976-1978 measured by us.

We consider the heavy metal data as representing fairly well the total concentrations, i.e. dis- 
Table 1. Concentrations of heavy metals in the Dead Sea, measured by Anodic Stripping Voltammetry $\left(\mu \mathrm{g} 1^{-1}\right)$.

\begin{tabular}{|c|c|c|c|c|c|c|c|c|c|}
\hline \multirow[t]{2}{*}{ Date } & \multirow[t]{2}{*}{ Depth } & \multicolumn{2}{|l|}{$\mathrm{Zn}$} & \multicolumn{2}{|l|}{$\mathrm{Cd}$} & \multicolumn{2}{|l|}{$\mathrm{Pb}$} & \multicolumn{2}{|l|}{$\mathrm{Cu}$} \\
\hline & & $\mathbf{a}$ & $\mathrm{b}$ & $\mathbf{a}$ & $\mathrm{b}$ & $\mathbf{a}$ & b & $\mathrm{a}$ & $\mathbf{b}$ \\
\hline $6 / 25 / 76$ & $30 \mathrm{~m}$ & $\begin{array}{l}63 \\
65\end{array}$ & & $\begin{array}{l}0.35 \\
0.47\end{array}$ & & $\begin{array}{l}7.9 \\
9.7\end{array}$ & & $\begin{array}{l}1.6 \\
3.4\end{array}$ & \\
\hline $1 / 20 / 76$ & $130 \mathrm{~m}$ & $\begin{array}{l}334 \\
314\end{array}$ & & $\begin{array}{l}0.19 \\
0.33\end{array}$ & & $\begin{array}{l}45.3 \\
41.4\end{array}$ & & $\begin{array}{l}6.7 \\
6.7\end{array}$ & \\
\hline $8 / 17 / 78$ & $75 \mathrm{~m}$ & 232 & $\begin{array}{l}168^{\mathrm{c}} \\
132\end{array}$ & 0.90 & $\begin{array}{l}0.57^{\mathrm{c}} \\
0.60\end{array}$ & 18.8 & $\begin{array}{c}15.0^{c} \\
6.3\end{array}$ & $\begin{array}{l}\mathrm{d} \\
\mathrm{d}\end{array}$ & \\
\hline $8 / 15 / 78$ & $250 \mathrm{~m}$ & $\begin{array}{l}330 \\
313\end{array}$ & $\begin{array}{l}326^{c} \\
293\end{array}$ & 1.04 & $\begin{array}{l}1.06^{\mathrm{c}} \\
0.76\end{array}$ & $\begin{array}{r}6.5 \\
16.1\end{array}$ & $\begin{array}{l}16.1^{\mathrm{c}} \\
12.0^{\circ}\end{array}$ & $\begin{array}{l}d \\
d\end{array}$ & \\
\hline $12 / 18 / 80$ & $50 \mathrm{~m}$ & 406 & $\begin{array}{l}361^{\mathrm{c}} \\
389 \\
299\end{array}$ & $\begin{array}{l}0.76 \\
0.74\end{array}$ & $\begin{array}{l}0.89^{c} \\
0.92 \\
0.86\end{array}$ & $\begin{array}{l}17.3 \\
19.9\end{array}$ & $16.1^{\mathrm{c}}$ & $\begin{array}{r}14.8 \\
6.6 \\
7.7\end{array}$ & $\begin{array}{l}1.3 \\
4.6\end{array}$ \\
\hline $\begin{array}{l}9 / 28 / 82 \\
9 / 28 / 82\end{array}$ & $\begin{array}{r}15 \mathrm{~m} \\
200 \mathrm{~m}\end{array}$ & $\begin{array}{c}98 \\
730^{?}\end{array}$ & & $\begin{array}{l}0.32 \\
0.16\end{array}$ & & $\begin{array}{r}6.8 \\
13.2\end{array}$ & & $\begin{array}{l}5.2 \\
34^{?}\end{array}$ & \\
\hline $5 / 9 / 85$ & $80 \mathrm{~m}$ & $\begin{array}{l}88 \\
84\end{array}$ & & $\begin{array}{l}0.04 \\
0.03\end{array}$ & & $\begin{array}{l}2.4 \\
2.8\end{array}$ & & $\begin{array}{l}4.4 \\
4.4\end{array}$ & \\
\hline $7 / 25 / 83$ & End Brine & 871 & & 1.26 & & 44.5 & & 14.2 & \\
\hline
\end{tabular}

a Measured after $1: 1$ dilution and acidification

b Measured after acidification in undiluted samples

c Measured without acidification

d Extremely large $\mathrm{Cu}$ concentrations; contamination from $\mathrm{Cu}$ pipes is suspected (see text)

? These large concentrations cannot be easily explained and could be due to contamination

solved and particulate. This assumption is based on the following facts: (i) the estimated concentrations of particulate $\left(\mu \mathrm{g} \mathrm{l}^{-1}\right) \mathrm{Zn}, \mathrm{Cd}, \mathrm{Pb}$ and $\mathrm{Cu}$ are $0.1,0.024,0.26$ and 0.08 respectively; these constitute only a few percent of our measured values and are thus well within the experimental error between duplicate measurements (Table 1). The above estimates were obtained by multiplying the heavy metal content $\left(\mu \mathrm{g} \mathrm{g}^{-1}\right)$ of the Dead Sea sediments (Nissenbaum, 1974): $\mathrm{Zn} \mathrm{52,} \mathrm{Cd} \mathrm{12,} \mathrm{Pb}$ 13 and $\mathrm{Cu} 43$, by the concentration of particulates (excluding halite) larger than $0.4 \mu \mathrm{m}$ which is usually about $2 \mathrm{mg}^{-1}$ (upper limit about $5 \mathrm{mg} \mathrm{l}^{-1}$; Stiller, unpublished data). (ii) there was no systematic difference between the data of acidified and nonacidified samples suggesting that the concentration of heavy metals as particulates is indeed very small.

\section{Concentrations of heavy metals in halite}

The sediment traps collected two different types of halite: large crystals (about $1 \mathrm{~cm}$ in size) which grew on the exterior side of the trap wall and much smaller ones, which were collected at the bottom of the sediment trap together with settled particulate material. Both types of halite have been measured for heavy metal content, taking between 5 to $25 \mathrm{~g}$ for each analysis.

Halite which precipitated on the outside of the sediment trap is quite similar in its heavy metal content to that collected within the sediment trap (Table 2). The halite samples are extremely enriched with $\mathrm{Pb}$ and the sequence of coprecipitated metal concentrations is $\mathrm{Pb}>\mathrm{Cd}>\mathrm{Zn}>$ $\mathrm{Cu}$.

The metal concentrations in the halite crystal taken from core B 1 (see Fig. 1) are different from those of recently precipitated halite with less $\mathrm{Pb}$, 
Table 2. Heavy metals coprecipitated with halite from the Dead Sea $\left(\mathrm{ng} \mathrm{g}^{-1}\right)$.

\begin{tabular}{lrrrr} 
Sample description & \multicolumn{1}{c}{$\mathrm{Zn}$} & $\mathrm{Cd}$ & $\mathrm{Pb}$ & $\mathrm{Cu}$ \\
\hline $\begin{array}{l}\text { Halite from Sediment } \\
\text { Trap 'Wall', 70 m, }\end{array}$ & 114.6 & 414 & 2393 & 4.8 \\
$\begin{array}{l}\text { Feb 8-Mar 8, 1983 } \\
\text { Halite from Sediment }\end{array}$ & 53.8 & 368 & 1600 & 3.1 \\
$\begin{array}{l}\text { Trap, 70 m, } \\
\text { Feb 8-Mar 8, 1983 }\end{array}$ & & & & \\
$\begin{array}{l}\text { Halite crystal at } \\
80-85 \text { cm in core B1 }\end{array}$ & 105.2 & 80 & 589 & 15.6 \\
$\begin{array}{l}\text { NaCl (analytical } \\
\text { grade) }\end{array}$ & 38 & 0.12 & 30 & 26 \\
\hline
\end{tabular}

less $\mathrm{Cd}$ and more $\mathrm{Cu}$. Core $\mathrm{B} 1$ has been dated at its bottom by ${ }^{14} \mathrm{C}$ and the inferred age at the depth of the halite crystals is about 265 years (Stiller \& Chung, 1984). It seems that either different concentrations of heavy metals prevailed in the Dead Sea at that time of deposition or diagenetic processes that took place in the sediments have altered the heavy metal content of the buried halite.

For comparison with natural endogenic halite, concentrations of heavy metals in analytical grade $\mathrm{NaCl}$ are also given in Table 2 .

\section{Heavy metals in Lake Kinneret and in the End Brine}

It is of interest to compare the concentrations of the heavy metals in Lake Kinneret, which until 1964 was a major source of water for the Jordan River and thus should represent typical concentrations for the inflow into the Dead Sea with those of the Dead Sea prior to the 1979 overturn. Surface water from Lake Kinneret sampled on April 8, 1985 contained $117.5 \pm 1.5 \mu \mathrm{g}^{-1} \mathrm{Zn}$, $0.040 \pm 0.012 \mu \mathrm{g} \mathrm{l}^{-1} \mathrm{Cd}, 7.26 \pm 0.25 \mu \mathrm{g} \mathrm{l}^{-1} \mathrm{~Pb}$ and $3.6 \pm 0.5 \mu \mathrm{g} \mathrm{l}^{-1} \mathrm{Cu}(n=2)$. These data, compared with the oxic upper water mass of the Dead Sea in 1976, suggest that Cd had the longest residence time and $\mathrm{Zn}$ and $\mathrm{Cu}$ the shortest.

The concentrations of heavy metals in the sample of End Brine collected in July 1983 (Table 1) are larger than the average concentrations found in the Dead Sea of 1980 by a factor of 2.4 for $\mathrm{Zn}, 1.7$ for $\mathrm{Cd}, 2.5$ for $\mathrm{Pb}$ and 2.3 for $\mathrm{Cu}$. Each liter of End Brine (total dissolved salts about $495 \mathrm{~g} \mathrm{l}^{-1}$ ) represents about 2.5 liters of original Dead Sea brine, from which about $250 \mathrm{~g}$ $\mathrm{NaCl}$ and $30 \mathrm{~g} \mathrm{KCl}$ have been deposited in the solar evaporation ponds. This estimate of 2.5 liters is based on the concentrations of bromine and of calcium which behave as conservative elements during the evaporation process (only about $1 \mathrm{~g}$ of calcium sulphate is being deposited) and are found to be more concentrated in the End Brine by a factor of 2.6 and 2.3 respectively (Epstein, 1976). Our heavy metal data in the End Brine therefore seem reasonable and indicate that there is no loss of $\mathrm{Zn}, \mathrm{Pb}$ and $\mathrm{Cu}$ during the evaporation process and only some of the $\mathrm{Cd}$, which has the greatest affinity for coprecipitation with $\mathrm{NaCl}$ (see Discussion), is being lost.

However, it is unclear why the heavy metals are not coprecipitated with $\mathrm{NaCl}$ in the evaporation ponds. One possible answer could be that the coprecipitation process is $\mathrm{pH}$ dependent and in the evaporation ponds the $\mathrm{pH}$ is actually decreasing with increasing concentration of dissolved salts, from pH 6.2 in the Dead Sea to $\mathrm{pH} 4.5$ in the End Brine (Stiller et al., 1985). To confirm or refute our explanation, experiments of halite precipitation at different $\mathrm{pH}$ 's and measurements of its heavy metal content as well as that of halite actually deposited in the evaporation ponds should be performed.

\section{Discussion}

The load of heavy metals in the Dead Sea: 1976-1985

It is evident that the physical and chemical changes which occurred in the Dead Sea during 1976-1985 have affected the vertical distribution and concentrations of the heavy metals. We have attempted to follow the temporal variations in the mass balances of the heavy metals during this 
period, although the number of samples which has been analysed is very limited; spatial variations, if any existed, are not represented.

\section{Zinc}

The concentrations of $\mathrm{Zn}$ in the deep waters in 1976 and in 1978 are similar, about $320 \mu \mathrm{g} \mathrm{l}^{-1}$. The higher concentration of the upper layer in 1978,150 or $176 \mu \mathrm{g} \mathrm{l}^{-1}$, is due to the deepening of the pycnocline and is close to that predicted by mass balance, $167 \mu \mathrm{g} \mathrm{l}^{-1}$. Consequently, both inventories of 1976 and of 1978 (Table 3) are about 32000 ton $\mathrm{Zn} /$ lake.

After the overturn of 1979 one would expect to find a $\mathrm{Zn}$ concentration of about $220 \mu \mathrm{g} \mathrm{l}^{-1}$ throughout the mixed water column. But the $\mathrm{Zn}$ concentration at $50 \mathrm{~m}$ in December 1980 was 300 to $400 \mu \mathrm{g}^{-1}$, which if representative for a mixed lake, would yield too large a load. The concentration of $730 \mu \mathrm{g} \mathrm{l}^{-1}$ in the deep waters of 1982 is also very hard to explain and is attributed to contamination. We have attempted to estimate $\mathrm{Zn}$ load of the lake in 1982 by relying only on the concentration of the upper layer, $98 \mu \mathrm{g} \mathrm{l}^{-1}$; it yields about 14000 ton/lake. This is in reasonable agreement with a concentration of $87 \mu \mathrm{g}^{-1}$ at $80 \mathrm{~m}$ and a total load of 12500 ton/lake in May 1985.

The amount of halite estimated to have been formed within the Dead Sea during 1982-1985 is about 330 million tonnes (Stiller, unpublished

Table 3. Estimates of heavy metals content in the Dead Sea 1976-1985 (tonnes/lake).

\begin{tabular}{lllllr}
\hline Year & $\begin{array}{l}\text { Volume } \\
3 \mathrm{~km}\end{array}$ & $\mathrm{Zn}$ & $\mathrm{Cd}$ & $\mathrm{Pb}$ & $\mathrm{Cu}$ \\
\hline 1976 & 146.2 & 32130 & 116 & 4300 & 730 \\
1978 & 146.2 & 32090 & 106 & 2440 & $?$ \\
1980 & 146.2 & 43550 & 109 & 2595 & 900 \\
1982 & 145.0 & 14210 & $?$ & 1800 & 755 \\
1985 & 143.4 & 12330 & 4.3 & 373 & 635 \\
$\begin{array}{l}\text { Predicted copre- } \\
\text { cipitation with }\end{array}$ & $18-24$ & $121-130$ & $560-790$ & 1 \\
halite (approx.) & & & & \\
\hline
\end{tabular}

data). The estimated coprecipitation of $\mathrm{Zn}$ with this amount of halite, being only about 20 tonnes, does not affect the $\mathrm{Zn}$ load of the lake. Other processes are responsible for the diminished mass of $\mathrm{Zn}$; one of them could be scavenging by clay particles entrained to settle by the sedimentation of the halite crystals.

\section{Cadmium}

The measured concentration in the deep waters of $1976,0.2-0.3 \mu \mathrm{g}^{-1}$, is probably inaccurate as there is no apparent explanation for how it could have become larger by a factor of four in the deep isolated waters in 1978. Therefore we assume it to have been about the same as that measured in 1978 , namely $1.05 \mu \mathrm{g}^{-1}$. This assumption is also supported by a calculation of the expected $\mathrm{Cd}$ concentration in 1978 in the upper $175 \mathrm{~m}$, as the pycnocline descended to that depth. By mixing the upper $80 \mathrm{~m}$ thick layer of 1976 containing $0.41 \mu \mathrm{g} \mathrm{l}^{-1}$ with the 1976 transition zone (down to $110 \mathrm{~m}$ and having an intermediate content of $0.74 \mu \mathrm{g}^{-1}$ ), and with the deep waters down to $175 \mathrm{~m}$ which supposedly contained $1.05 \mu \mathrm{g} 1^{-1}$, an average concentration of $0.66 \mu \mathrm{g} \mathrm{l}^{-1}$ is obtained. This is in reasonable agreement with the measured concentration in the upper $175 \mathrm{~m}$ in 1978: $0.57-0.61 \mu \mathrm{g} \mathrm{Cd}$ per liter. If this argument is acceptable then the load of $\mathrm{Cd}$ in 1976 becomes very similar to that of 1978,116 and 106 tonnes respectively.

In 1980 , the measured value of $0.75 \mu \mathrm{g} \mathrm{l}^{-1}$ seems to represent well the homogenous water column and yields an inventory which is comparable with the two previous ones.

In September 1982, the Cd concentrations are unexpectedly smaller yielding a total mass of $\mathrm{Cd}$ which is well below that of earlier estimates. At that date, formation of halite had not yet started (it was first observed in November 1982) and no loss due to coprecipitation can be invoked. The $\mathrm{Zn}$ inventory of 1982 has the same unexplained feature; it could be that the samples of 1982 have been affected by mishandling.

Coprecipitation with 330 million tonnes of 
halite, from November 1982 to May 1985, can account for the loss of 125 tonnes of $\mathrm{Cd}$ from the water column (assuming $0.38 \mu \mathrm{g} \mathrm{Cd}$ per $\mathrm{g} \mathrm{NaCl}$, see Table 2). The inventory of $\mathrm{Cd}$ in 1985 , of less than 5 tonnes seems therefore in agreement with expectation. It should be mentioned however that 125 tonnes could be an overestimate as the concentration of $0.38 \mu \mathrm{g} \mathrm{Cd} \mathrm{g}^{-1} \mathrm{NaCl}$ may have diminished as the water column became more and more depleted in $\mathrm{Cd}$.

\section{Lead}

The $\mathrm{Pb}$ content of the lake in 1976, about 4300 tonnes is the largest of the 1976-1985 survey. Then a sharp decrease in the lake's load of $\mathrm{Pb}$ is observed in 1978. The progressive deepening of the pycnocline is reflected in the relatively larger $\mathrm{Pb}$ concentration of the upper layer in 1978, but its measured content is somewhat lower than that predicted by mass balance calculation $\left(22.4 \mu \mathrm{g}^{-1}\right)$. It could be that this discrepancy, as well as the striking loss of $\mathrm{Pb}$ from the deep waters of 1978 (concentration decreased from 43 to $16 \mu \mathrm{g} \mathrm{l}^{-1}$ ) are related to scavenging of $\mathrm{Pb}$ from the water column by settling iron hydroxide particles, freshly formed at the downward moving oxic/anoxic boundary. In freshwater Lake Zurich (Sigg et al., 1987) $\mathrm{Cd}, \mathrm{Cu}$ and $\mathrm{Zn}$ are less affected by scavenging with iron hydroxides than $\mathrm{Pb}$; the correlation coefficient between $\mathrm{Fe}$ and the heavy metals in settling material decreases from 0.78 for $\mathrm{Pb}$, through $\mathrm{Cu}$ and $\mathrm{Zn}$ to 0.35 for $\mathrm{Cd}$. It could be that a similar scavenging pattern takes place in hypersaline lakes as well. Concentrations and inventories of dissolved $\mathrm{Pb} 210$ in August 1978 (Stiller \& Kaufman, 1984) featured a similar behavior with that of stable $\mathrm{Pb}$, namely a considerable loss from the water column.

In 1980 the $\mathrm{Pb}$ load is comparable with that of 1978, suggesting that the 1979 turnover did not affect it. In 1982, like the diminished loads of $\mathrm{Zn}$ and $\mathrm{Cd}$, the decreasing load of $\mathrm{Pb}$ also remains unexplained.

The expected coprecipitation with halite during $1982-1985$ is estimated to have possibly with- drawn between 500 to 800 tonnes $\mathrm{Pb}$ from the water column. But the inventory of 1985 indicates that about 1200 tonnes are missing. Unless the coprecipitated quantity is underestimated (it is based on a single sediment trap), and while variations in different areas of the lake and at different times cannot be ruled out, other scavenging processes such as that by clay particles must have been involved.

\section{Copper}

The loads of $\mathrm{Cu}$ are almost constant during 1976-1985, about 700-800 ton/lake and the amount expected to coprecipitate with halite in $1982-1985$ is practically negligible, only about 1 ton. Thus it seems that the load of $\mathrm{Cu}$ was almost unaffected by changes in redox conditions and endogenic chemical precipitation which took place in the water column during the period of our survey.

However, there are slight fluctuations in the inventories of $\mathrm{Cu}$ which simultaneously resemble those of the other heavy metals: an increase is observed in 1980 and a decrease in 1982 which continues into 1985 .

\section{Coprecipitation of heavy metals with halite}

The apparent distribution coefficient is estimated by dividing the ratio between the heavy metal and $\mathrm{Na}$ concentrations in halite to that in the Dead Sea brine. For the heavy metal content of the brines we will use average data from 1980 instead the data from 1982 when precipitation of $\mathrm{NaCl}$ had actually started, because we do not yet have a plausible explanation for the smaller concentrations measured at that later date. The $\mathrm{Na}$ concentration in the Dead Sea was $40.6 \mathrm{~g} \mathrm{I}^{-1}$ (Steinhorn, 1985 ) and in halite it is $0.393 \mathrm{~g} \mathrm{~g}^{-1}$ halite.

Table 4 shows that although the $\mathrm{Pb}$ concentration in halite is the greatest, it is $\mathrm{Cd}$ which has the largest distribution coefficient. Two additional points should be noted: (1) the atomic radius of $\mathrm{Cd}^{2+}$ happens to be exactly the same as that of 
Table 4. Estimated apparent distribution coefficients of the heavy metals for halite precipitating from the Dead Sea.

\begin{tabular}{llcll}
\hline & $\mathrm{Zn}$ & $\mathrm{Cd}$ & $\mathrm{Pb}$ & $\mathrm{Cu}$ \\
\hline Halite $\left(\mathrm{ng} \mathrm{g}^{-1}\right)^{\mathrm{a}}$ & $66.7 \pm 43.1$ & $385.7 \pm 24.8$ & $1895 \pm 433$ & $4.4 \pm 1.1$ \\
Dead Sea $\left(\mu \mathrm{g}^{-1}\right)^{\mathrm{b}}$ & $363 \pm 47$ & $0.84 \pm 0.08$ & $17.8 \pm 1.4$ & $6.3 \pm 1.6$ \\
K app & 0.019 & 47.3 & 11.0 & 0.04 \\
\hline
\end{tabular}

a Average of 3 measurements on halite collected by sediment traps in 1983 (see Table 2)

b average of heavy metals concentrations in the Dead Sea in 1980 (see Table 1)

$\mathrm{Na}^{+}$, namely $0.97 \AA$, this may facilitate its incorporation into the halite crystal lattice; (2) the magnitudes of $\mathrm{K}$ app are almost in the same decreasing order $\mathrm{Cd}>\mathrm{Pb}>\mathrm{Cu}>\mathrm{Zn}$ as are the strengths of the chloro complexes of the heavy metals: $\mathrm{Cd}>\mathrm{Pb}>\mathrm{Zn}>\mathrm{Cu}$ (Long \& Angino, 1977).

The decrease in the inventories of the heavy metals was generally larger than predicted by coprecipitation with halite (Table 3 ). The predictions assumed constant concentrations of heavy metals in the Dead Sea; this is an overestimate because in fact the coprecipitated amounts, especially for $\mathrm{Cd}$ and $\mathrm{Pb}$, would even decrease with decreasing concentrations in the Dead Sea. One possible explanation for the discrepancy between predicted and observed loads of heavy metals in 1985 could be the following: the formation of halite particles, as it increases the number of particles per unit volume, causes a larger number of collisions between suspended particles, possibly weakening their colloidal stability and producing aggregates. The precipitation of halite may thus have enhanced the formation and settling of aggregates. If the heavy metals were somehow attached to otherwise stable colloidal particles, (bound to their surfaces; Sigg et al., 1982) or were susceptible to being scavenged by these aggregates, this could be a possible way for their elimination from the water column. Supporting evidence for such a process is provided by sediment trap data (Stiller, Gat and Spencer, unpublished data). Prior to November 1982 the settling flux of particulates was usually about $0.06-0.11 \mathrm{mg} \mathrm{cm}^{-2}$ day $^{-1}$ during summer and winter respectively. It has increased suddenly to about $0.9-1.1 \mathrm{mg} \mathrm{cm}^{-2}$ day $^{-1}$ at the onset of halite precipitation in
November 1982 and has persisted at this enhanced rate until April 1983. Then fluxes of particulates diminished back to the regular values mentioned above.

\section{Acknowledgement}

This study was performed while M. Stiller benefited from the hospitality of EAWAG on her sabbatical leave. Stimulating discussions with Prof. W. Stumm and the cooperative attitude of the colleagues at EAWAG are gratefully acknowledged.

\section{References}

Anati, D. A., M. Stiller, S. Shasha \& J. R. Gat, 1987. Changes in the thermohaline structure of the Dead Sea: 1979-1984. Earth Planet. Sci. Lett; 84: 109-121.

Bard, H. J. \& L. R. Faulkner, 1980. Electrochemical methods - Fundamentals and applications. J. Wiley, New York, 718 pp.

Bentor, Y. K., 1961. Some geochemical aspects of the Dead Sea and the question of its age. Geochim. Cosmochim. Acta 25: 239-260.

Brooks, R. R., B. J. Presley \& I. R. Kaplan, 1967. APDC MIBK extraction system for the determination of trace metals in saline waters by atomic absorption spectrophotometry. Talanta 14: 809-816.

Epstein, A. J., 1976. Utilization of Dead Sea minerals (a review) Hydrometallurgy 2: 1-10.

Long, D. T. \& E. E. Angino, 1977. Chemical speciation of Cd, $\mathrm{Cu}, \mathrm{Pb}$ and $\mathrm{Zn}$ in mixed freshwater, seawater and brine solutions. Geochim. Cosmochim. Acta 41: 1183-1191.

Neev, D. \& K. O. Emery, 1967. The Dead Sea. Geol. Survey Isr. Bull. No. 41, 147 pp.

Nishri, A. \& M. Stiller, 1984. Iron in the Dead Sea. Earth Planet. Sci. Lett. 71: 405-414.

Nissenbaum, A., 1974. Trace elements in Dead Sea sediments. Israel J. Earth Sci. 23: 111-116. 
Nissenbaum, A., 1977. Minor and trace elements in Dead Sea water. Chem. Geol. 19: 99-111.

Schoenfeld, L. \& S. Held, 1965. Spectrochemical methods for determining $\mathrm{B}, \mathrm{Ba}, \mathrm{Li}$ and $\mathrm{Rb}$ in Mediterranean and Dead Sea water. IAEC Report IA-1061, 17 pp.

Sigg, L., M. Sturm, J. Davis \& W. Stumm, 1982. Metal transfer mechanisms in lakes. Thalassia Jugoslavica 18: 293-311.

Sigg, L., M. Sturm \& D. Kistler, 1987. Vertical transport of heavy metals by settling particles in Lake Zurich. Limnol. Oceanogr. 32: 112-130.

Steinhorn, I., 1983. In situ salt precipitation at the Dead Sea. Limnol. Oceanogr. 28: 580-583.

Steinhorn, I., 1985. The disappearance of the long term meromictic stratification of the Dead Sea. Limnol. Oceanogr. 30: 451-472.

Steinhorn, I., G. Assaf, J. R. Gat, A. Nissenbaum, M. Stiller, M. Beyth, D. Neev, R. Garber, G. M. Friedman \& W. Weiss, 1979. The Dead Sea: Deepening of the mixolimnion signifies the overture to overturn of the water column. Science 206: 55-57.

Stiller, M. \& A. Kaufman, 1984. Pb-210 and Po-210 during the destruction of stratification in the Dead Sea. Earth Planet. Sci. Lett. 71 : 390-404.

Stiller, M. \& Y. C. Chung, 1984. Radium in the Dead Sea: a possible tracer for the duration of meromixis. Limnol. Oceanogr. 29: 574-586.

Stiller, M., J. R. Gat, N. Bauman \& S. Shasha, 1984a. A short meromictic episode in the Dead Sea: 1979-1982. Verh. int. Ver. Limnol. 22: 132-135.

Stiller, M., M. Mantel \& M. S. Rapaport, 1984b. The determination of trace elements $(\mathrm{Co}, \mathrm{Cu}$ and $\mathrm{Hg}$ ) in the Dead Sea by neutron activation followed by $\mathrm{X}$-ray spectrometry and magnetic deflection of beta-ray interference. J. Radioanalyt. Nucl. Chem. 83: 345-352.

Stiller, M., J. S. Rounick \& S. Shasha, 1985. Extreme carbon isotope enrichments in evaporating brines. Nature 316 : 434-435. 